\title{
Application of Choynowski's Memory Scale in assessment of patients with dementia
}

\author{
Konrad Janowski ${ }^{1}$, Katarzyna Gustaw², Małgorzata Kasprowicz ${ }^{3}$
}

1Department of Psychology, University of Finance and Management, Warsaw, Poland 2Department of Neurodegenerative Diseases, Institute of Agricultural Medicine, Lublin, Poland

3Institute of Psychology, John Paul II Catholic University of Lublin, Poland

Submitted: 5 May 2010

Accepted: 25 June 2010

Arch Med Sci 2012; 8, 1: 130-137

DOI: 10.5114/aoms.2012.27293

Copyright (c) 2012 Termedia \& Banach

\section{Abstract}

Introduction: Neuropsychological assessment of patients with dementia necessitates the use of varied memory tasks designed to measure different memory processes, including information memorization, retention and retrieval. A valid memory battery should be demonstrated to discriminate between demented and non-demented subjects and its scores should be related to the degree of intellectual impairment. The objective of this study was to evaluate the potential usefulness of Choynowski's Memory Scale in assessment of patients with dementia. Material and methods: Thirty-two patients with dementia and 64 age- and gender- matched healthy controls took part in the study. All participants were examined by means of Choynowski's Memory Scale, and the patients were additionally assessed by the Mini Mental State Examination and Clock Drawing Test (CDT). Results: All subtests of Choynowski's Memory Scale were found to highly significantly $(p \leq 0.001)$ discriminate between patients with dementia and healthy controls. Except for Digit Span, all other subtests of Choynowski's battery were highly correlated with the global mental status as assessed by MMSE with correlation coefficients ranging from 0.59 to 0.81 . Most subtests of Choynowski's Memory Scale were also moderately or highly correlated with performance on the CDT, and the correlations coefficients between the total score on Memory Scale and the CDT were $r=0.66$ and $r=0.61(p \leq 0.001)$ for the free recall drawing and copying, respectively.

Conclusions: Choynowski's Memory Scale showed high discriminative properties and strong associations with the degree of intellectual impairment in dementia. The results encourage the use of this battery in clinical settings.

Key words: memory assessment, clock drawing test, dementia diagnosis, Alzheimer disease, vascular dementia.

\section{Introduction}

Dementia is a complex psychopathological syndrome characterized by impairments in cognition and behaviour with resulting subsequent decline in activities of daily living [1]. Neuropsychological assessment constitutes a crucial part of the diagnosis of dementia and involves measurement of various cognitive, emotional and psychosocial functions carried out by means of standardized tests. Memory functions are among the most important to be measured as the first complaints which motivate the patients or their family members to seek professional advice typically concern mem-
Corresponding author: Konrad Janowski PhD, Department of Psychology University of Finance and Management 55 Pawia

01-030 Warsaw, Poland Phone: +48 225365421 E-mail: janowski@vizja.pl 
ory impairment. Memory functions have been demonstrated to show subtle impairments as long as 9 years before the clinical diagnosis of dementia [2] and to be one of the best discriminating factors between healthy subjects and those who will later develop Alzheimer disease [3]. In the clinical phase of the disease, monitoring the changes in the levels of memory dysfunctions may also provide important clues as to the progress rate of dementia and is taken into account when defining consecutive stages of the disease process $[4,5]$.

Assessment of memory functions was suggested not only to be indicative of the level of general intellectual impairment but also to be useful in diagnosing the type of dementia $[6,7]$. The rationale for use of memory tests in differentiating dementias of various types lies in the fact that various memory functions involve anatomically diverse cerebral structures or systems which in turn are differentially affected by neuropathological processes leading to dementias. For instance, impairments of memory information storage were linked to lesions of the limbic system and particularly the hippocampus, retrieval dysfunctions were associated with damage to the frontal-subcortical circuits, and shortterm memory failures were attributed to temporoparietal lesions [8].

A thorough assessment of different memory dysfunctions requires application of a battery of tasks which are able to reliably measure isolated memory processes. Preferably, information learning, storage and retrieval should be assessed separately as they were shown to be differentially affected in mild cognitive impairment, Alzheimer disease, vascular dementia, dementia with Lewy bodies and frontotemporal dementia [9-12]. Also, both auditory and visual stimuli should be covered to address various information input modalities. Some authors even suggested the discriminative value of olfactory stimuli [13]. Finally, the conditions for various information retrieval methods should be utilized such as immediate vs. delayed retrieval, free recall vs. cued recall, or recall vs. recognition $[14,15]$.

There is a range of well-standardized memory tests, such as the Benton Visual Retention Test (BVRT), Rey Verbal Learning Test (RVLT), and Digit Span, which are commonly used for various diagnostic purposes in patients with suspected or actual dementia and which usually measure a single, selected aspect of memory. The most popular memory test batteries, which combine tasks addressing separately various memory functions and involving procedures for various information retrieval methods, include the Wechsler Memory Scale- $3^{\text {rd }}$ Edition, and the Free and Cued Selective Reminding Test. Their application in the context of the diagnosis of intellectual decline is common and recommended [16].
However, the use of these test batteries in Poland is impossible, since, so far, no Polish adaptations are available. When carrying out neuropsychological assessments in patients with suspected intellectual deterioration, Polish psychologists either resort to tests measuring single memory processes (BVRT, RVLT) or apply a battery of experimental memory tasks which most commonly lack normalization and appropriate standardization, and therefore do not fully meet the psychometric requirements expected for this type of diagnostic instruments [17].

Choynowski's Memory Scale is a test battery consisting of various memory tasks developed by Mieczysław Choynowski in Poland in 1959. Due to the fact that no normalization has ever been done, the scale has almost been forgotten and is uncommon in memory assessment in clinical settings. However, a closer examination of this test battery reveals that it has certain properties which can make it a very useful instrument in dementia-related assessment. First, it contains tasks that address both auditory and visual stimuli, thus enabling an evaluation of different memory modalities. Second, these tasks involve various memory processes and information retrieval methods, including immediate and delayed recall, free and cued recall, shortterm memory (digit span) and learning speed. Finally, the battery already possesses carefully developed, unified instructions for administration and scoring procedures, which provides a basis for standardized psychometric measurement [18].

Appreciating the advantages of Choynowski's Memory Scale, we have already undertaken research with the purpose of developing up-to-date norms for this test. As part of this research we carried out a study to examine whether this scale may prove sensitive in memory assessment in the context of dementia diagnosis. Therefore, the objectives of this study were to evaluate the potential utility of Choynowski's Memory Scale to discriminate dementia patients from healthy controls and to assess the associations between Choynowski's Memory Scale and the degree of the global intellectual decline in dementia.

\section{Material and methods}

\section{Participants}

Thirty-two patients with a previously established diagnosis of dementia, or with suspected dementia in whom the diagnosis was later confirmed, took part in the study. The patients were recruited into the study when they presented to a doctor for medical advice in the Department of Neurodegenerative Diseases, Institute of Agricultural Medicine. The group consisted of 17 patients with the diagnosis of Alzheimer's disease (AD) and 15 patients with vascular dementia (VaD). The diagnoses were consistent with the Diagnostic and Statistical Manual 
of Mental Disorders, 4th edition (DSM-IV) criteria and National Institute of Neurological and Communicative Disorders and Stroke-AD and Related Disorders Association (NINCDS-ADRDA) criteria for possible or probable AD. The Modified Hachinski Ischemic Score [19] was determined; all the patients with vascular dementia had a composite score of 5 or more and imaging study consistent with vascular dementia. Computed tomography (CT) or magnetic resonance imaging (MRI) scans were obtained routinely for all patients.

Patients included in the study had to be otherwise healthy and ambulatory or ambulatory aided (i.e., walker or cane), with vision and hearing sufficient for compliance with the testing procedures. Laboratory test values had to be within normal limits or considered to be clinically insignificant by the physician. All patients had to have a reliable caregiver. Patients were excluded if they had evidence of clinically significant and unstable, active gastrointestinal, renal, hepatic, endocrine, or systemic disease, primary psychiatric diseases (notably DSMIV-defined depression), newly treated hypothyroidism, or a known or suspected history (within the past 10 years) of alcoholism or drug abuse. Additional reasons for exclusion included evidence of neoplasm, insulin-dependent diabetes or diabetes not stabilized by diet or oral hypoglycaemic agents, obstructive pulmonary disease or asthma, recent ( $<2$ years) haematological/oncological disorders, pernicious anaemia, or vitamin $\mathrm{B}_{12}$ or folate deficiency as evidenced by blood concentrations below the lower normal limit.

The control group comprised 64 healthy subjects whose scores were taken from the already existing pool of normative data obtained from approximately 700 subjects. The controls were among the persons who had been recruited into the study on the normalization of Choynowski's Memory Scale, and the exclusion criteria were as follows: a known central nervous system disease (dementia, epilepsy, Parkinson's disease, or other), a history of cerebrovascular disorders (including strokes), traumatic brain injury, and severe psychiatric disorders (schizophrenia, severe depression). For each patient with dementia, two random controls were selected out of those who matched the patient by age and gender. We failed to find four control subjects who matched the patients by exact age, so the controls whose age was closest (within the range of two years) to the patient were selected.

The study was carried out in accordance with the Institute of Agricultural Medicine Bioethical Commission agreement. After complete description of the study protocol, written informed consent was obtained from the patients (if possible), the caregivers, or the patient's representative (if applicable) before beginning detailed screening activities.

\section{Psychological testing}

Choynowski's Memory Scale is a memory test battery consisting of tasks addressing various aspects of memory:

1) Auditory Memory - with immediate free recall of 20 pieces of information from a short story; the raw scores range from 0 to 20;

2) Digit Span - examines short-term memory and attention; the scores range from 0 to 14;

3) Picture Memory - visual stimuli (12 pictures of common objects) are presented for $24 \mathrm{~s}$ with subsequent free recall; the scores range from 0 to 12;

4) Learning Speed - measures the number of trials necessary to memorize a sentence read aloud by the examiner. The raw score is then reversed, so that the higher score indicates better performance and the lower score worse performance; the scores range from 1 to 11;

5) Digit Span Reversed - measures short-term memory and intellectual flexibility activated by the repetition of digit series in a reversed order; the scores range from 0 to 12 ;

6) Visual Retention - examines the precision of retention of visually presented geometric figures which are drawn by the subject following the exposure; the scores range from 0 to 14;

7) Associate Pairs - examines the recall of a list of words associated with other cue words (cued recall); the scores range from 0 to 21 ;

8) Delayed Recall - examines the delayed recall of the 20 pieces of information provided in the first task of the battery (Auditory Memory); the scores range from 0 to 20 .

The raw scores obtained in each task are summed up to yield the total score - a global measure of memory processes. The theoretical range for the total score is from 1 to 124 [18].

Mini Mental State Examination (MMSE) - is the most commonly used measure of the global mental status used in screening for dementia [20]. The scale examines the following functions:

1) orientation to time and place;

2) memorization of 3 words;

3) attention (subtraction of 7s from 100);

4) recall of previously memorized words;

5) language functions (naming, repetition, command comprehension, reading, writing);

6) visual-spatial abilities (praxis - copying a picture of two overlapping pentagons).

The advantages of this instrument include the short time needed for its administration, yielding a quantitative result, uncomplicated administration procedure and good tolerability on the part of patients [21]. Correct performance in all the tasks is scored 30 points. The most commonly accepted cut-off threshold for dementia is 23 points; however, the scores of MMSE were demonstrated to be dependent on age and education level, and the 
norms have been proposed adjusted for these variables [22].

The Clock Drawing Test (CDT) is a simple, nonverbal screening test used in diagnosis of dementia. There are several variants of this test differing in particulars concerning the reproduction method (copying a pre-drawn clock vs. free drawing), time which the subject is instructed to indicate (3:00 vs. $08: 20$ vs. 11:10) and scoring system (qualitative vs. quantitative) [23]. In our study, we followed the administration procedure suggested by Shah [24] and the scoring system developed by Manos [25] as they combine simplicity with a possibility of quantitative scoring and of obtaining further qualitative information relevant for clinical diagnosis.

In accordance with Shah's [24] recommendations, each patient was first given a sheet of paper with a pre-drawn circle signifying the clock face and asked to complete it with appropriate numbers and clock hands indicating 11:10 (the free drawing version). Then, the patient was given a complete, predrawn picture of the clock and instructed to copy it (the copying version). The free drawing version is assumed to examine language functions (verbal comprehension of the command), memory functions (recalling visual engrams stored in long-term memory and recalling the instruction on the time at which the clock hands were to be set - stored in short-term memory), and executive functions (planning, sequencing, organizing), which generally correspond to the temporal and frontal lobe activities. The copying version is less dependent on language and memory function, as it activates mainly perceptual and visual-spatial abilities associated with parietal lobe control.

The scoring system involved evaluation of the spatial correctness of the numbers written on the clock face and appropriateness of the clock hands showing the indicated time. One point was given for any of numbers 1, 2, 4, 5, 7, 8, 10 and 11 if they were placed in their correct octant of the clock face. One point was also given for the short hand indicating number 11, and for the long hand indi- cating number 2 . The possible score range is from 0 to 10, with higher scores indicating better performance. Scores lower than 8 indicate an increased likelihood of intellectual impairment and scores lower than 5 evidence severe intellectual impairment [25].

\section{Statistical analysis}

Results are presented as means $(M) \pm$ standard deviations $(S D)$. The differences between the patients and controls were tested by means of Student $t$ tests for independent groups. The associations between the scores on Choynowski's Memory Scale and the scores on MMSE and CDT were calculated as Pearson's $r$ correlation coefficients. The test of significance of the differences between correlation coefficients was also used. The results of statistical tests were considered significant at the level of $p<0.05$.

\section{Results \\ Participants' characteristics}

The match between the patients and controls was very good - no statistically significant differences were found between these groups in sex, age or residence (Table I).

The mean score obtained for the patients on MMSE was 19.42 although the variance in the scores was considerable, reflecting various degrees of intellectual decline ranging from severe to subtle. The mean scores in both the copying and free drawing versions of CDT were markedly lowered and within the diagnostic range for intellectual impairment. The mean performance in the copying version was better than in the free drawing version, and the difference was statistically significant ( $t=-3.67, p=0.001)$. For healthy controls, the mean score in MMSE was 29.03 and the range from 24 to 30 , indicating no impairment in cognitive functioning. Similarly, healthy controls' scores in both free drawing and copying versions of CDT fell with-

Table I. The sociodemographic characteristics of patients and control groups

\begin{tabular}{|c|c|c|c|c|}
\hline Characteristics & Patients with dementia & Healthy controls & Test statistic & Value of $p$ \\
\hline \multicolumn{5}{|l|}{ Age } \\
\hline Range (min-max) & $36-84$ & $36-84$ & - & - \\
\hline Mean $( \pm$ SD) & $69.78( \pm 10.86)$ & $69.59( \pm 10.18)$ & $t=0.83$ & 0.93 \\
\hline \multicolumn{5}{|l|}{ Sex, $n(\%)$} \\
\hline Men & $10(31.2 \%)$ & 20 (31.2\%) & \multirow[t]{2}{*}{$\chi^{2}=0.00$} & \multirow[t]{2}{*}{1.00} \\
\hline Women & $22(68.8 \%)$ & $44(68.8 \%)$ & & \\
\hline \multicolumn{5}{|l|}{ Residence, $n$ (\%) } \\
\hline Urban & 26 (81.3\%) & $39(60.9 \%)$ & \multirow[t]{2}{*}{$\chi^{2}=4.59$} & \multirow[t]{2}{*}{0.10} \\
\hline Rural & $6(18.7 \%)$ & 25 (39.1\%) & & \\
\hline
\end{tabular}


Table II. The clinical characteristics of the patients and control groups as measured by MMSE and CDT. The differences between the means for patients and controls were highly statistically significant for all the indices

\begin{tabular}{|lcccc|}
\hline \multirow{2}{*}{ Variables } & \multicolumn{2}{c}{ Patients with dementia } & \multicolumn{2}{c|}{ Healthy controls } \\
\cline { 2 - 5 } & Range & Mean $( \pm$ SD $)$ & Range & Mean $( \pm$ SD) \\
\hline MMSE & $0-10$ & $6.28( \pm 3.18)$ & $8-10$ & $9.94( \pm 0.30)$ \\
\hline Orientation & $0-3$ & $2.53( \pm 0.92)$ & $3-3$ & $3.00( \pm 0.00)$ \\
\hline Memorization & $0-5$ & $1.78( \pm 1.81)$ & $2-5$ & $4.56( \pm 0.89)$ \\
\hline Attention & $0-3$ & $1.44( \pm 1.22)$ & $1-3$ & $2.72( \pm 0.58)$ \\
\hline Recall & $0-8$ & $6.53( \pm 1.93)$ & $7-8$ & $7.89( \pm 0.31)$ \\
\hline Language & $0-1$ & $0.41( \pm 0.50)$ & $0-1$ & $0.92( \pm 0.27)$ \\
\hline Praxis & $3-30$ & $19.42( \pm 6.41)$ & $24-30$ & $29.03( \pm 1.48)$ \\
\hline Total & & & & $9.66( \pm 0.82)$ \\
\hline CDT & $0-10$ & $3.63( \pm 3.89)$ & $7-10$ & $9.92( \pm 0.27)$ \\
\hline Free drawing & $0-10$ & $5.89( \pm 3.41)$ & $9-10$ & \\
\hline Copying & & & & \\
\hline
\end{tabular}

in the normative range, with means of 9.66 and 9.92, respectively (Table II).

\section{Performance on Choynowski's Memory Scale}

All subscales of Choynowski's Memory Scale were found to discriminate patients with dementia and healthy controls, with very significantly higher scores observed in the control group. The differences between the two groups were most prominent for the total score. Detailed results obtained for both groups are presented in Table III, and Figures 1 and 2.

\section{Choynowski's Memory Scale and Performance} on MMSE and CDT in patients with dementia

Almost all subtests of Choynowski's Memory Scale showed very significant correlations with the MMSE global score, with the strongest association noted for the total score. Digit Span was the only subtest of Choynowski's Memory Scale unrelated to global mental status and to most of its components as measured by individual MMSE tasks. No significant associations were observed between any of the tasks in Choynowski's Memory Scale and the mental status component of Memorization. It is of note that individual subtests of Choynowski's Memory Scale showed diverse correlational patterns with components of mental status examination (Table IV).

The total score on Choynowski's Memory Scale was significantly positively correlated with both the free drawing and copying versions of CDT. Again, Digit Span was the only memory subtest unrelated to either of the CDT versions. In contrast, Digit Span Reversed showed the highest correlations with both variants of CDT. When the correlation coefficients for particular memory tasks and the free drawing or copying versions of CDT were compared, no statistically significant differences were found (Table V). This suggests no significant differences in the strength of the associations between the scores on Choynowski's Memory Scale and the two versions of CDT.

Table III. Performance on Choynowski's Memory Scale in the patients and control groups

\begin{tabular}{|c|c|c|c|c|}
\hline \multirow[t]{2}{*}{ Choynowski's Memory Scale } & \multirow{2}{*}{$\begin{array}{c}\text { Patients with dementia } \\
\text { Mean }( \pm S D)\end{array}$} & \multirow{2}{*}{$\begin{array}{c}\text { Healthy controls } \\
\text { Mean ( } \pm \text { SD) }\end{array}$} & \multicolumn{2}{|c|}{ Student's $t$ test } \\
\hline & & & $t$ & $p$ \\
\hline Auditory Memory & $3.21( \pm 3.69)$ & $7.71( \pm 4.23)$ & -4.87 & 0.00 \\
\hline Digit Span & $2.18( \pm 1.12)$ & $3.50( \pm 1.57)$ & -4.57 & 0.00 \\
\hline Pictures Memory & $3.96( \pm 2.50)$ & $6.67( \pm 1.83)$ & -5.81 & 0.00 \\
\hline Learning Speed & $1.57( \pm 1.29)$ & $3.19( \pm 2.81)$ & -3.79 & 0.00 \\
\hline Digit Span Reversed & $1.57( \pm 1.37)$ & $2.73( \pm 1.29)$ & -3.91 & 0.00 \\
\hline Visual Retention & $2.89( \pm 2.78)$ & $7.09( \pm 4.08)$ & -5.74 & 0.00 \\
\hline Associate Pairs & $6.79( \pm 5.56)$ & $11.09( \pm 3.93)$ & -3.72 & 0.00 \\
\hline Delayed Recall & $3.57( \pm 4.17)$ & $7.56( \pm 4.22)$ & -4.19 & 0.00 \\
\hline Total & $25.39( \pm 18.37)$ & $48.84( \pm 16.40)$ & -6.07 & 0.00 \\
\hline
\end{tabular}




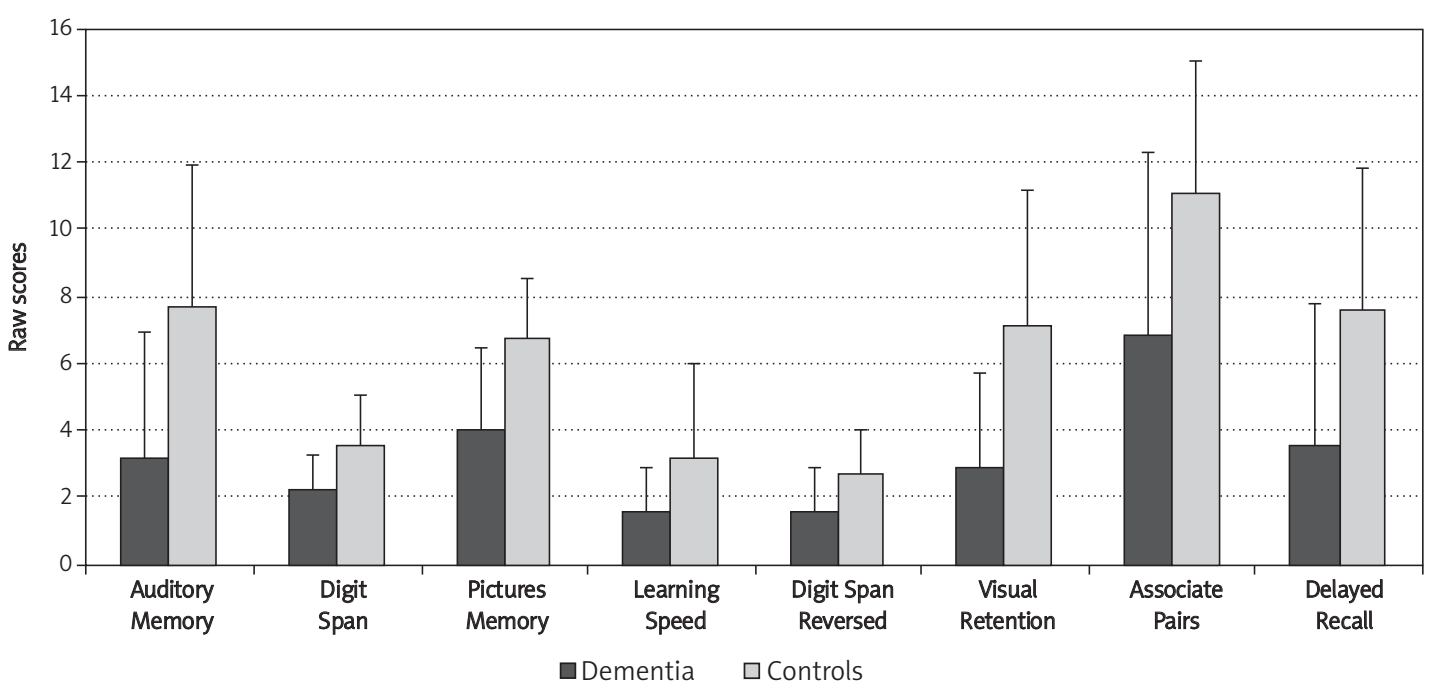

Figure 1. The mean (+ SD) raw scores on Choynowski's Memory Scale tasks in patients with dementia and in healthy controls

\section{Discussion}

In our study we aimed to evaluate the utility of Choynowski's Memory Scale in assessment of patients with dementia. When performances on the subtests of this scale were compared between patients with dementia and healthy controls, very significant differences were found between the groups in all tasks. The differences between dementia patients and healthy individuals on various memory scales have been reported by numerous authors and reflect memory disruption which usually occurs as one of the first symptoms in most dementia syndromes [26]. Therefore, a valid memory task battery that is intended to be used in clinical settings for the purposes of dementia diagnosis should show a high potential to discriminate between dementia patients and healthy subjects.

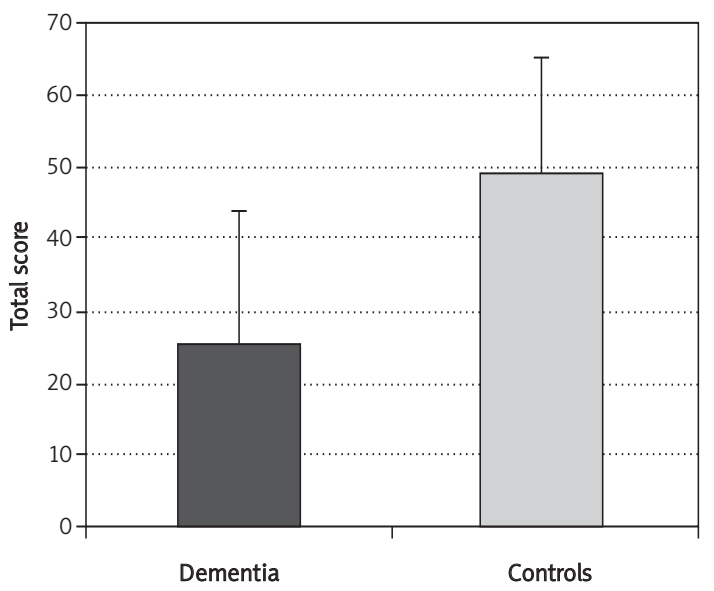

Figure 2. The mean (+ SD) total scores on Choynowski's Memory Scale in patients with dementia and healthy controls

Table IV. Pearson's $r$ correlation coefficients between the scores on Choynowski's Memory Scale and MMSE in patients with dementia

\begin{tabular}{|c|c|c|c|c|c|c|c|}
\hline \multirow{2}{*}{$\begin{array}{l}\text { Choynowski's } \\
\text { Memory Scale }\end{array}$} & \multicolumn{7}{|c|}{ MMSE } \\
\hline & Orientation & Memorization & Attention & Recall & Language & Praxis & Total \\
\hline Auditory Memory & $0.68^{* * *}$ & 0.06 & $0.46^{\star}$ & $0.38^{*}$ & 0.24 & 0.07 & $0.66^{* * \star}$ \\
\hline Digit Span & 0.31 & 0.17 & 0.09 & -0.05 & 0.20 & -0.06 & 0.25 \\
\hline Pictures Memory & $0.53^{\star *}$ & 0.15 & 0.36 & $0.56^{\star *}$ & 0.23 & 0.22 & $0.62^{\star \star \star}$ \\
\hline Learning Speed & $0.46^{\star}$ & 0.20 & $0.55^{\star *}$ & 0.36 & 0.13 & 0.33 & $0.59^{\star * *}$ \\
\hline Digit Span Reversed & $0.51^{\star \star}$ & -0.02 & $0.71^{\star \star *}$ & 0.22 & $0.47^{\star}$ & 0.26 & $0.68^{\star * *}$ \\
\hline Visual Retention & $0.51^{\star \star}$ & 0.02 & $0.63^{\star * \star}$ & 0.23 & 0.37 & $0.43^{*}$ & $0.65^{\star \star *}$ \\
\hline Associate Pairs & $0.68^{* * *}$ & 0.04 & $0.63^{\star \star \star}$ & $0.56^{\star *}$ & 0.35 & 0.27 & $0.79^{\star \star *}$ \\
\hline Delayed recall & $0.65^{* * *}$ & 0.08 & $0.49^{\star *}$ & $0.55^{\star *}$ & 0.16 & 0.17 & $0.68^{\star * *}$ \\
\hline Total & $0.72^{\star \star \star}$ & 0.17 & $0.60^{\star \star \star}$ & $0.50^{\star *}$ & 0.33 & 0.29 & $0.81^{\star \star \star}$ \\
\hline
\end{tabular}

${ }^{*} p<0.05,{ }^{* *} p<0.01,{ }^{* * *} p<0.001$ 
Table V. Pearson's $r$ correlation coefficients between the scores on Choynowski's Memory Scale and CDT in patients with dementia

\begin{tabular}{|lccc|}
\hline Choynowski's Memory Scale & \multicolumn{2}{c}{ CDT } & $\begin{array}{c}\text { Significance of the difference } \\
\text { between the correlation coefficients }\end{array}$ \\
\cline { 2 - 4 } & Free drawing & Copying & $p$ \\
\hline Auditory Memory & $0.52^{*}$ & $0.55^{* *}$ & 0.44 \\
\hline Digit Span & -0.07 & 0.18 & 0.17 \\
\hline Pictures Memory & 0.36 & $0.44^{*}$ & 0.36 \\
\hline Learning Speed & $0.57^{* *}$ & 0.38 & 0.17 \\
\hline Digit Span Reversed & $0.78^{* * *}$ & $0.72^{* * *}$ & 0.30 \\
\hline Visual Retention & $0.72^{* * *}$ & $0.55^{* *}$ & 0.14 \\
\hline Associate Pairs & $0.67^{* * *}$ & $0.62^{* * *}$ & 0.37 \\
\hline Delayed Recall & $0.53^{*}$ & $0.44^{*}$ & 0.33 \\
\hline Total & $0.66^{* * *}$ & $0.61^{* * *}$ & 0.38 \\
\hline${ }^{*} p<0.05,{ }^{* *} p<0.01,{ }^{* * *} p<0.001$ & & & \\
\hline
\end{tabular}

Our findings provide support for high sensitivity of Choynowski's Memory Scale in differentiating patients with dementia from non-demented subjects.

Additionally, the scores on almost all tasks of Choynowski's Memory Scale were significantly associated with the degree of global intellectual decline as measured by MMSE. This finding suggests that Choynowski's Memory Scale can be used not only for the purpose of discriminating healthy subjects and dementia patients but can also be utilized in patients already diagnosed with dementia to monitor the progress of the disease or potential effectiveness of applied therapies [5, 27, 28].

The only task of Choynowski's Memory Scale which was found to be unrelated to the global mental status as measured by MMSE was Digit Span. A similar finding, however, was also reported in other studies, showing that this task is not sensitive to dementia [29]. It follows from our results that it is Digit Span Reversed rather than Digit Span alone that is much more sensitive to dementia-related intellectual decline. The lack of significant correlations between Choynowski's Memory Scale and the mental state component of Memorization probably followed from low variance in the latter task. The repetition of the three words in MMSE is usually unaffected up to severe stages of dementia, which leads to a greatly reduced variance of scores. However, it is also possible that the memory tasks included in Choynowski's Memory Scale are not actually related to performance in this subcomponent of the mental status.

Most of the tasks of Choynowski's battery were also shown in our study to correlate with performance on CDT, and these findings attest to the fact that actual memory disruption, as captured by Choynowski's scale, is significantly related to executive dysfunctions, as measured by CDT. This may add to the evidence on validity of Choynowski's scale. No statistically significant differences between the correlations for the free drawing or copying version of CDT and Choynowski's scale were observed in our study. This suggests that even though the scores on Choynowski's memory tasks are related to executive functions, they may not discriminate between more subtle differences in executive dysfunctions, as captured by the free drawing and copying versions of CDT. This finding seems noteworthy for the interpretation of Choynowski's scale scores in the context of cognitive impairment diagnosis, as data from the literature indicate that patients with most types of dementia usually reveal worse performance in the free drawing version than in the copying version of CDT [30], and this distinction may not be reflected in the scores of Choynowski's Memory Scale.

Three of the memory tasks, i.e. Digit Span Reversed, Visual Retention and Associate Pairs, showed highly significant correlations with both CDT versions, and the total score in Choynowski's Memory Scale revealed strong correlations with both the free drawing and copying versions of CDT. This confirms the sensitivity of Choynowski's battery to various degrees of intellectual decline in dementia, as measured by CDT. As CDT and MMSE address slightly different aspects of the mental status, with MMSE emphasizing orientation and verbal functions and CDT putting stress on visual-spatial abilities [17], the differences in the correlation pattern between memory tasks and these two measures of global intellectual impairment are natural and could be expected.

In conclusion, this study was, to our knowledge, the first attempt to validate Choynowski's Memory Scale in patients with dementia. We demonstrated that all tasks from this battery showed high- 
ly significant differences between patients with dementia and healthy controls, and that scores on most of these tasks were significantly correlated with the degree of intellectual decline in dementia. Our findings provide support for the potential usefulness of this instrument in clinical settings, particularly in the situation when no standardized multidimensional memory battery is currently available for clinical diagnosis in Poland.

A limitation of our study is the small sample size of patients with dementia and a deviation from the perfect match between the patients and controls with respect to age. Therefore, further research on larger patient samples is needed, particularly in order to calculate the precise sensitivity and specificity of Choynowski's Memory Scale in detecting dementia. Future studies are also required to investigate the potential usefulness of this tool in differentiating patients with diverse types of dementia.

\section{References}

1. Flirski M, Sobow T, Kloszewska I. Behavioural genetics of Alzheimer's disease: a comprehensive review. Arch Med Sci 2011; 7: 195-210.

2. Amieva H, Jacqmin-Gadda H, Orgogozo JM, et al. The 9 year cognitive decline before dementia of the Alzheimer type: a prospective population-based study. Brain 2005; 128: 1093-101.

3. Chen P, Ratcliff G, Belle SH, Cauley JA, DeKosky ST, Ganguli M. Patterns of cognitive decline in presymptomatic Alzheimer disease: a prospective community study. Arch Gen Psychiatry 2001; 58: 853-8.

4. Feldman $\mathrm{HH}$, Woodward $\mathrm{M}$. The staging and assessment of moderate to severe Alzheimer disease. Neurology 2005; 65 (Suppl 3): S10-7.

5. Locascio JJ, Growdon JH, Corkin S. Cognitive test performance in detecting, staging, and tracking Alzheimer's disease. Arch Neurol 1995; 52: 1087-99.

6. Massman PJ, Kreiter KT, Jankovic J, Doody RS. Neuropsychological functioning in cortical-basal ganglionic degeneration: differentiation from Alzheimer's disease. Neurology 1996; 46: 720-6.

7. Perri R, Koch G, Carlesimo GA, et al. Alzheimer's disease and frontal variant of frontotemporal dementia: a very brief battery for cognitive and behavioural distinction. J Neurol 2005; 252: 1238-44.

8. Pasquier F. Early diagnosis of dementia: neuropsychology. J Neurol 1999; 246: 6-15.

9. de Jager CA. Changes over time in memory, processing speed and clock drawing tests help to discriminate between vascular cognitive impairment, mild cognitive impairment and Alzheimer's disease. Neurol Res 2004; 26: 481-7.

10. Reed BR, Mungas DM, Kramer JH, et al. Profiles of neuropsychological impairment in autopsy-defined Alzheimer's disease and cerebrovascular disease. Brain 2007; 130: 731-9.

11. Snowden JS, Neary D, Mann DMA. Fronto-temporal lobar degeneration, fronto-temporal dementia, progressive aphasia, semantic dementia. Churchill-Livingstone, New York 1996.

12. Stavitsky K, Brickman AM, Scarmeas N, et al. The progression of cognition, psychiatric symptoms, and fun- ctional abilities in dementia with Lewy bodies and Alzheimer disease. Arch Neurol 2006; 63: 1450-6.

13. Gilbert PE, Murphy C. The effect of the ApoE epsilon4 allele on recognition memory for olfactory and visual stimuli in patients with pathologically confirmed Alzheimer's disease, probable Alzheimer's disease, and healthy elderly controls. J Clin Exp Neuropsychol 2004; 26: 779-94.

14. Ivanoiu A, Adam S, Van der Linden M, et al. Memory evaluation with a new cued recall test in patients with mild cognitive impairment and Alzheimer's disease. J Neurol 2005; 252: 47-55.

15. Westerberg CE, Paller KA, Weintraub S, et al. When memory does not fail: familiarity-based recognition in mild cognitive impairment and Alzheimer's disease. Neuropsychology 2006; 20: 193-205.

16. Petersen RC, Smith GE, Waring SC, Ivnik RJ, Tangalos EG, Kokmen E. Mild cognitive impairment: clinical characterization and outcome. Arch Neurol 1999; 56: 303-8.

17. Paulsen JS, Hoth KF. Neuropsychology. In: Bradley WG, Daroff RB, Fenichel GM, Jankovic J (eds.). Neurology in clinical practice. Vol. I: Principles of diagnosis and management. 4th ed. Butterworth-Heinemann 2004; 675-700.

18. Choynowski M. Skala pamięci. (Memory scale). Polish Academy of Sciences, Psychometric Laboratory Warsaw 1959.

19. Rosen WG, Terry RD, Fuld PA, Katzman R, Peck A. Pathological verification of ischemic score in differentiation of dementias. Ann Neurol 1980; 7: 486-8.

20. Folstein MF, Folstein SE, McHugh PR. "Mini-mental state". A practical method for grading the cognitive state of patients for the clinician. J Psychiatr Res 1975; 12: 189-98.

21. Folstein FM, Robins LN, Helzer JE. The Mini-Mental State Examination. Arch Gen Psychiatry 1983; 40: 812.

22. Crum RM, Anthony JC, Basset SS, Folstein MF. Populationbased norms for the Mini-Mental State Examination by age and educational level. JAMA 1993; 269: 2386-91.

23. Libson DJ, Swenson RA, Barnoski EJ, Sands LP. Clock drawing as an assessment tool for dementia. Arch Clin Neuropsychol 1993; 8: 405-15.

24. Shah J. Only time will tell: clock drawing as an early indication of neurological dysfunction. P\&S Med Rev 2001; 7: 30-4.

25. Manos PJ. The utility of the ten-point clock test as a screen for cognitive impairment in general hospital patients. Gen Hosp Psychiatry 1997; 19: 439-44.

26. Wicklund AH, Johnson N, Rademaker A, Weitner BB, Weintraub $\mathrm{S}$. Word list versus story memory in Alzheimer disease and frontotemporal dementia. Alzheimer Dis Assoc Disord 2006; 20: 86-92.

27. Johannsen P, Salmon E, Hampel H, et al. Assessing therapeutic efficacy in a progressive disease: a study of donepezil in Alzheimer's disease. CNS Drugs 2006; 20: 311-25.

28. Cachia D, Swearer J, Ferguson W, Moonis M. Selective cognitive patterns resulting from bilateral hippocampal ischemia. Arch Med Sci 2011; 7: 168-72.

29. Linn RT, Wolf PA, Bachman DL, et al. The 'preclinical phase' of probable Alzheimer's disease. A 13-year prospective study of the Framingham cohort. Arch Neurol 1995; 52: 485-90.

30. Gnanalingham KK, Byrne EJ, Thornton A, Sambrooks MA, Bannister P. Motor and cognitive function in Lewy body dementia: comparison with Alzheimer's and Parkinson's disease. J Neurol Neurosurg Psychiatry 1997; 62: 243-52. 